\title{
Simultaneous Estimation of Metoprolol Succinate and Olmesartan Medoxomil in Pharmaceutical Formulation by Thin-Layer Chromatographic-Densitometric Method
}

\author{
Sunil L. Baldania, Ankit B. Parmar, Kashyap K. Bhatt, \\ Dimal A. Shah, and Usmangani K. Chhalotiya \\ Department of Pharmaceutical Chemistry and Analysis, Indukaka Ipcowala College of Pharmacy, Gujarat, \\ New Vallabh Vidyanagar 388121, India \\ Correspondence should be addressed to Sunil L. Baldania, sl_baldania@yahoo.com
}

Received 10 March 2012; Accepted 2 May 2012

Academic Editors: L. Nei and M. I. Saleh

Copyright (C) 2012 Sunil L. Baldania et al. This is an open access article distributed under the Creative Commons Attribution License, which permits unrestricted use, distribution, and reproduction in any medium, provided the original work is properly cited.

A new, simple, accurate, and precise high-performance thin-layer chromatographic (HPTLC) method is described for simultaneous analysis of metoprolol succinate and olmesartan medoxomil in pharmaceutical formulations. The separations were achieved on prepared TLC plates precoated with silica gel G $60 \mathrm{~F}_{254}$ and the plates were developed with methanol-ethyl acetatetoluene-glacial acetic acid $2.5: 3: 4.5: 0.3 \% \mathrm{v} / \mathrm{v} / \mathrm{vas}$ mobile phase. Detection and evaluation of chromatograms were performed densitometrically at $224 \mathrm{~nm}$. The retention factor of metoprolol succinate and olmesartan medoxomil was 0.25 and 0.70 , respectively. The linear range was 1000-2250 $\eta \mathrm{g}$ per spot for metoprolol succinate and 800-1800 $\eta \mathrm{g}$ per spot for olmesartan medoxomil and the correlation coefficients $(r)$ were 0.993 and 0.999 , respectively. The method was validated for linearity and range, specificity, precision, accuracy, and robustness, and the results were found to be within the acceptance criteria. The method was successfully applied to the analysis of drugs in their capsule dosage form.

\section{Introduction}

Metoprolol succinate (MET) is chemically 1-[4-(2methoxyethyl)-phenoxy]-3-[(1-methylethylamino]-2-

propanol. It is a beta adrenergic blocking agent, which reduces chest pain and lowers high blood pressure (Figure 1). It is official in BP, USP [1].

Olmesartan medoxomil (OLM) is an angiotensin II type 1 receptor blocker (Figure 1). It works by blocking a substance in the body that causes blood vessels to tighten. As a result, OLM relaxes blood vessels. This lowers blood pressure and increases the supply of blood and oxygen to the heart. It is not official in IP, BP, and USP [2].

These drugs are nowadays available in combination therapy. The rationale behind use of this drug combination is that in treatment of hypertension in patients whose blood pressure is not adequately controlled by monotherapy, oral administration of metoprolol succinate and olmesartan medoxomil has been found to be more effective than the use of either drug alone.

Literature survey revealed that various spectrophotometric and chromatographic methods have been reported for estimation of MET [3-11] and OLM [12-18] individually or in combination with other drugs. To the best of our knowledge, there is no HPTLC method reported for analysis of metoprolol succinate and olmesartan medoxomil in pharmaceutical formulations. Hence, the aim of the present study is to establish accurate and sensitive method and, after validation in accordance with International Conference on Harmonization (ICH) guidelines, to use the method for analysis of the drug content of both in capsule dosage form.

\section{Experimental}

2.1. Chemicals and Materials. Analytically pure samples of MET and OLM were obtained as gift samples from 


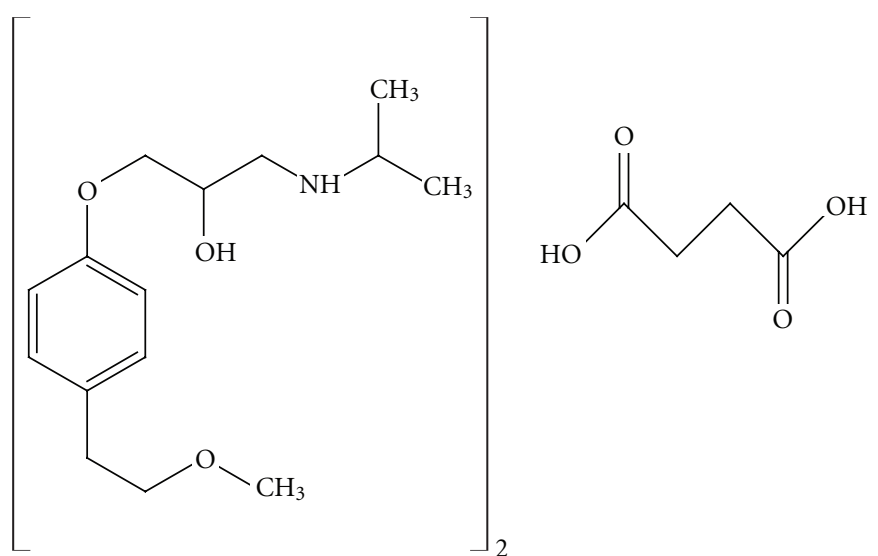

(a)

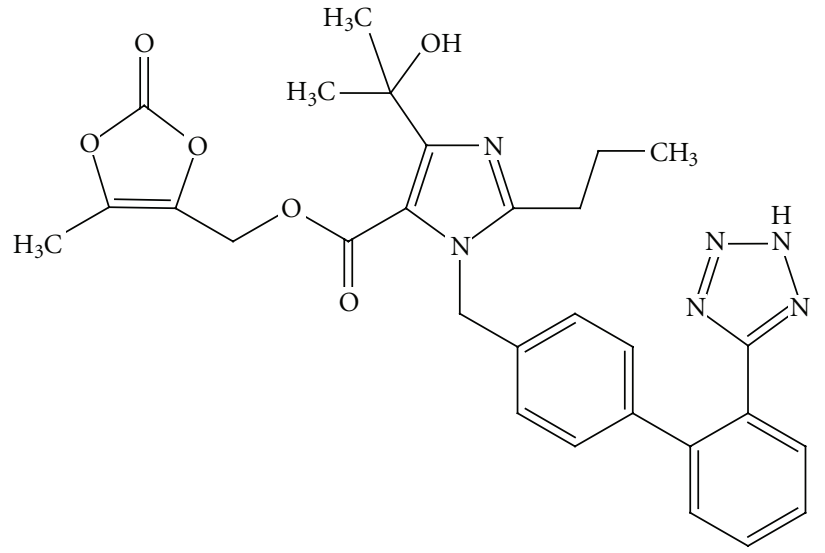

(b)

FIGURE 1: Structure of metoprolol succinate (a) and olmesartan medoxomil (b).

Alembic Pharmaceuticals Ltd. (Baroda, India). Methanol, ethyl acetate, toluene, and glacial acetic acid used were of analytical grade (Astron Chemicals, India). Capsule formulation A (Olsar M 25, Unichem Laboratories Ltd., India) and formulation B (Olmax M 25, Glenmark Pharmaceuticals Ltd., India) containing labeled amount of $25 \mathrm{mg}$ of MET and $20 \mathrm{mg}$ of OLM, were procured from local market.

2.2. Chromatographic Conditions. Chromatography was performed on $10 \mathrm{~cm} \times 10 \mathrm{~cm}$ aluminum HPTLC plates precoated with silica gel of $250 \mu \mathrm{m}$ thickness (E. Merck, Darmstadt, Germany; supplied by Anchrom Technologists, Mumbai, India). The plates were prewashed by methanol and activated at $110^{\circ} \mathrm{C}$ for $25 \mathrm{~min}$ prior to chromatography. Samples were applied as $6 \mathrm{~mm}$ wide bands by means of CAMAG (Muttenz, Switzerland) Linomat V sample applicator fitted with $100 \mu \mathrm{L}$ applicator syringe (Hamilton, Bonaduz, Switzerland). A constant application rate of $0.1 \mu \mathrm{L} / \mathrm{s}$ was employed and the space between two adjacent bands was $5 \mathrm{~mm}$. The plates were then conditioned for $20 \mathrm{~min}$ in a presaturated twin-trough glass chamber $\left(10 \times 10 \mathrm{~cm}^{2}\right)$ with the mobile phase of methanol-ethyl acetate-toluene-glacial acetic acid $2.5: 3: 4.5: 0.3(\% \mathrm{v} / \mathrm{v} / \mathrm{v})$ in one trough and plates in the other trough. The plates were then placed in the mobile phase and ascending development was performed to a distance of $70 \mathrm{~mm}$ from the point of application at ambient temperature, and the development time was $12 \mathrm{~min}$. Subsequent to the development, the plates were dried in a current of air with the help of an air dryer and spots were visualized in CAMAG UV cabinet with dual wavelength UV lamp (254 and $366 \mathrm{~nm}$ ); densitometric scanning was performed at $224 \mathrm{~nm}$ with CAMAG TLC scanner III operating in reflectance-absorbance mode and controlled by WinCats software (version 1.3.4).

The slit dimensions were $6.0 \times 0.45 \mathrm{~mm}$ at $20 \mathrm{~mm} \mathrm{~s}^{-1}$ scanning speed. The concentrations of compound were studied from the intensity of diffusely reflected light. Evaluation was based on linear regression of peak areas.
2.3. Preparation of Standard Solution. A stock solution was prepared by dissolving accurately weighed $25 \mathrm{mg}$ of MET and $20 \mathrm{mg}$ of OLM with $10 \mathrm{~mL}$ methanol. Aliquots of this solution were suitably diluted with methanol to get working standard solutions of MET and OLM in the concentration of $250 \mu \mathrm{g} \mathrm{mL} L^{-1}$ for MET and $200 \mu \mathrm{g} \mathrm{mL} L^{-1}$ for OLM. Standard solutions of MET and OLM were prepared to get concentration range of $1000-2250 \mathrm{ng}$ per spot and 800-1800 ng per spot, respectively, by dilution of working standard solution with methanol.

2.4. Method Validation. The developed method was validated for linearity and range, specificity, accuracy, precision, limit of detection, limit of quantitation, robustness, and solution stability as per ICH guidelines.

2.4.1. Linearity and Range. Each concentration in the range of 1000-2250 ng per spot for MET and 800-1800 ng per spot for OLM was spotted five times on individual plates and response was measured after scanning. For evaluation of linearity, peak area and concentrations were subjected to least square regression analysis to calculate calibration equation and correlation coefficient.

2.4.2. Specificity. The specificity of the method was ascertained by analyzing MET and OLM in presence of excipients commonly used for capsule formulations. The bands of MET and OLM were confirmed by comparing $R_{F}$ values and respective spectra of sample with those of standards. The peak purity of MET and OLM was assured by comparing the spectra at three different levels, that is, peak start, peak apex, and peak end positions.

2.4.3. Accuracy (\%Recovery). The accuracy of the method was determined by recovery studies using method of standard additions to laboratory-made synthetic mixture. Known amounts of MET and OLM were added at three 
different levels (approx 80, 100, and 120\% of label claim) to constant weight of synthetic mixture of placebo, respectively. The accuracy was then calculated from the test results as the percentage of analyte recovered by the assay.

2.4.4. Method Precision (Repeatability). Repeatability of measurement of peak area was checked by repeated scanning of the same spot $(n=6)$ of metoprolol succinate $(1500 \mu \mathrm{g}$ per band) and olmesartan medoxomil (1200 $\mu$ g per band) without changing the position of the plate. Repeatability of sample application was assessed by spotting metoprolol succinate $(1500 \mu \mathrm{g}$ per band) and olmesartan medoxomil (1200 $\mu$ g per band) six times on an HPTLC plate, developing the plate and recording peak area for the spots. The precision of the method was evaluated by calculating the percent relative standard deviation (\%RSD) of mean peak areas obtained from each spot of sample.

2.4.5. Intermediate Precision (Reproducibility). The intraday and interday precision of the method was determined by estimating the corresponding response three times on the same day and on three different days over a period of one week for three different concentrations of metoprolol succinate $(1000,1500$, and $2250 \eta$ g per band) and olmesartan medoxomil (800, 1200, and $1800 \eta \mathrm{g}$ per band). Again here, the precision of the method was evaluated by calculating the percent relative standard deviation (\%RSD) of mean peak areas obtained from each spot of sample.

\subsubsection{Limits of Detection (LOD) and Limits of Quantitation} (LOQ). Limits of detection (LOD) and quantitation (LOQ) were determined as signal-to-noise ratio using the equations $\mathrm{LOD}=3.3 \times N / B$ and $\mathrm{LOQ}=10 \times N / B$, where $N$ is the standard deviation of the peak areas of the drugs $(n=5)$, taken as a measure of the noise, and $B$ is the slope of the calibration curve.

2.4.7. Robustness. In order to establish the robustness of the method, small deliberated changes were made in the experimental conditions and chromatographic parameters like change in plate activation time, chamber saturation time $( \pm 20 \%$ change from set time), volume of mobile phase $( \pm 10 \%$ change from set volume), and development distance $( \pm 10 \%$ change from set distance). In the abovechanged conditions, stock solution was analyzed and results of robustness studies were expressed in terms of \%RSD of peak areas in each changed condition and were compared with similar results obtained in unchanged experimental conditions.

2.4.8. Solution Stability. The solutions at analytical concentration (MET-250 $\mathrm{g} \mathrm{mL}^{-1}$, OLM-200 $\mu \mathrm{g} \mathrm{mL}^{-1}$ ) were prepared and stored at room temperature for $24 \mathrm{~h}$ and analyzed at intervals of $0,6,12$, and $24 \mathrm{~h}$ for the presence of any band other than that of MET and OLM and the results were simultaneously compared with the freshly prepared standard solution of MET and OLM standard solution of the same

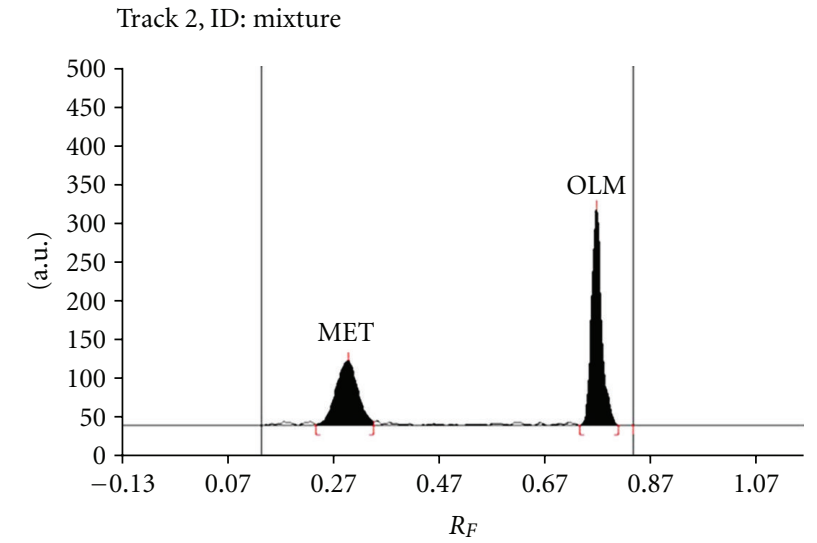

FIgURE 2: HPTLC densitogram of metoprolol succinate and olmesartan medoxomil when scanning at $224 \mathrm{~nm}$.

concentration in the form of change in $\%$ RSD of the response obtained.

\subsection{Application of Validated Method to Pharmaceutical For-} mulation. To determine the content of MET and OLM in combined dose capsule formulation, twenty capsules of each brand were weighed; powder from the capsules was removed and the empty capsule shells were reweighed. Difference in the weight expressed the weight of powder present in twenty capsules. Average weight was calculated and capsule powder equivalent to about $25 \mathrm{mg}$ MET and $20 \mathrm{mg}$ OLM was transferred to $25 \mathrm{~mL}$ volumetric flask $10 \mathrm{~mL}$ of methanol was added, and content of the flask was ultrasonicated for 10 minutes. The solution was filtered through Whatman filter paper no. 41. and filter paper was washed with methanol twice and volume was then made up to the mark with methanol. From the filtrate, $1.0 \mathrm{~mL}$ was diluted to $10.0 \mathrm{~mL}$ with methanol. On TLC plate two bands of standard and four bands of sample solution were applied and the plate was developed and scanned under the optimized chromatographic conditions. After scanning, the peaks obtained for standard and sample bands were integrated. Amount of the drugs present in applied volume of sample solution was obtained by comparison between peak area of standard and sample bands. Five samples were prepared and analyzed in similar manner.Thus the validated method was used for analysis of metoprolol succinate and olmesartan medoxomil in their combined capsules dosage form (brand A and B).

\section{Results and Discussion}

3.1. Method Development and Optimization of Chromatographic Conditions. Selection of best solvent system is the critical step in HPTLC method development. From the different solvent systems tried, mobile phase consisting of methanol-ethyl acetate-toluene-glacial acetic acid in the ratio $2.5: 3: 4.5: 0.3(\% \mathrm{v} / \mathrm{v} / \mathrm{v})$ resulted in better separation which gave symmetric peaks of MET with $R_{F}$ of 0.25 and OLM with $R_{F}$ of 0.70 (Figure 2). Well-defined bands were obtained 


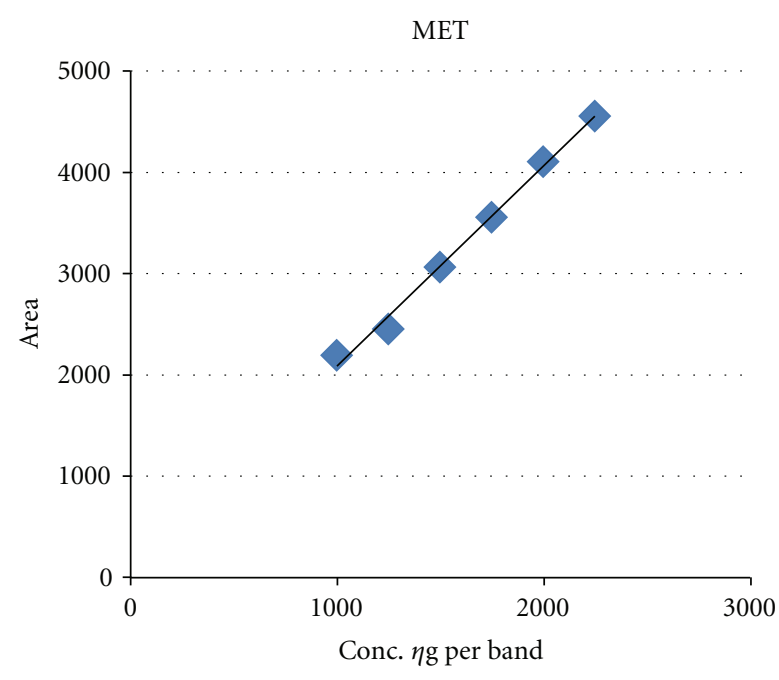

(a)

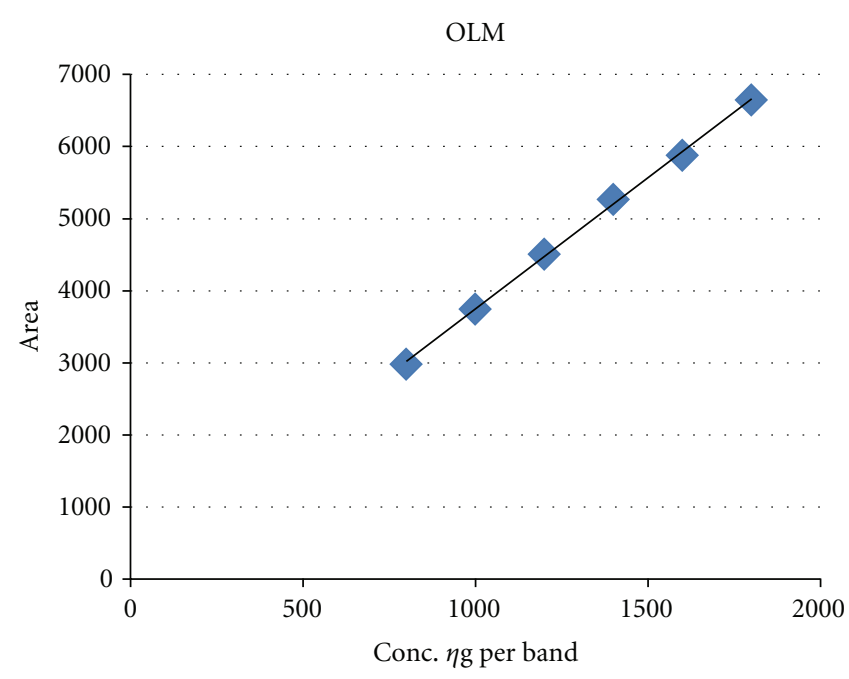

(b)

FIGURE 3: Calibration plot of MET and OLM by the developed HPTLC method.

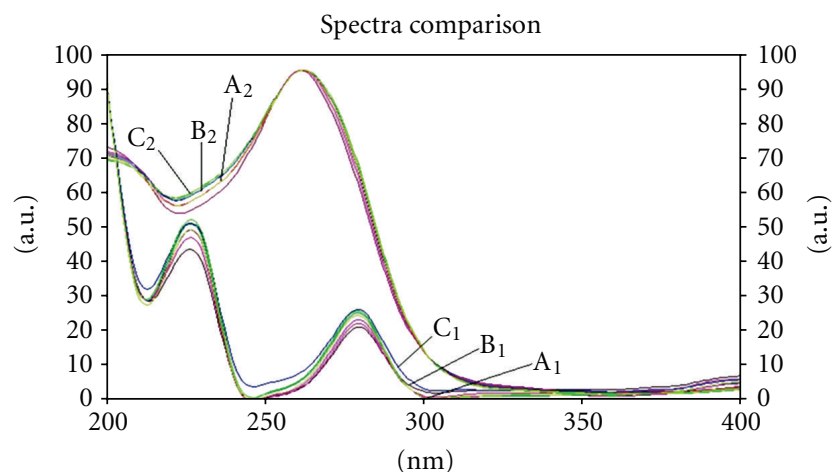

FIgURE 4: Spectra comparison of MET and OLM. $\left(\mathrm{A}_{1}\right.$ and $\left.\mathrm{A}_{2}\right)$ Bulk of MET and OLM, $\left(B_{1}\right.$ and $\left.B_{2}\right)$ capsule formulation $A$ and $\left(C_{1}\right.$ and $\mathrm{C}_{2}$ ) capsule formulation $\mathrm{B}$, respectively.

when the chamber was saturated with mobile phase for 20 min at ambient temperature. For quantitative purpose, the densitometric scanning was carried at wavelength $224 \mathrm{~nm}$ where MET and OLM exhibited good UV absorption.

\subsection{Validation of the Method}

3.2.1. Linearity. Linearity was observed over the concentration range of 1000-2250 ng per band for MET and 800$1800 \eta \mathrm{g}$ per band for OLM, respectively. The regression equations $(n=5)$ were $y=1.9736 x+116.42$ for MET and $y=3.6394 x+106.33$ for OLM, respectively, where $y$ is response and $x$ the amount chromatographed. The correlation coefficients $(r)$ were 0.993 and 0.999 , respectively, over these concentration ranges as shown in Figure 3.

3.2.2. Specificity. Specificity of the method for MET and OLM was proved from the spectral scan (Figure 4), and peak
TABLE 1: Peak purity correlation results of MET and OLM in two formulations at peak start, middle, and end.

\begin{tabular}{lcc}
\hline Sample & $\begin{array}{c}\text { Correlation of center and slope spectra } \\
r(s, m)\end{array}$ & $r(m, e)$ \\
\hline MET & 0.991 & 0.979 \\
MET capsule formulation A & 0.973 & 0.969 \\
MET capsule formulation B & 0.985 & 0.993 \\
OLM & 0.998 & 0.928 \\
OLM capsule formulation A & 0.906 & 0.936 \\
OLM capsule formulation B & 0.946 & 0.954 \\
\hline
\end{tabular}

purity correlation $(r)$ results (Table 1 ) for MET and OLM in two capsule formulations indicate that there is no merging or coelution of interfering peaks with MET and OLM, so there is no interference from any excipients present in capsule formulation.

3.2.3. Accuracy. Accuracy of proposed method was studied by preparing synthetic mixtures of capsule excipients having a known amount of MET and OLM corresponding to approximately $80-120 \%$ of the label claim. Mean recovery was between $99.85-101.07 \%$ for MET and $99.08-101.29 \%$ for OLM, respectively, indicating that the developed method was accurate for the determination of MET and OLM in pharmaceutical formulations (Table 2).

3.2.4. Precision. For determination of precision of MET and OLM by the proposed method, same homogenous samples of MET and OLM were prepared repeatedly and analyzed. Intermediate precision was evaluated at different times on the same day and on different days. Low values of RSD (less than $2 \%$ ) obtained in the studies indicate that the method is precise and reproducible (Table 3 ). 
TABLE 2: Results from accuracy study.

\begin{tabular}{|c|c|c|c|c|c|c|c|c|}
\hline \multirow{2}{*}{ Level } & \multicolumn{2}{|c|}{ Amount of drug added (mg) } & \multicolumn{2}{|c|}{ Amount of drug found (mg) } & \multicolumn{2}{|c|}{ Mean recovery ${ }^{(\mathrm{a})}(\%)$} & \multicolumn{2}{|c|}{ \%RSD } \\
\hline & MET & OLM & MET & OLM & MET & OLM & MET & OLM \\
\hline \multirow{3}{*}{$80 \%$} & 4.50 & 3.60 & 4.49 & 3.65 & \multirow{3}{*}{99.85} & \multirow{3}{*}{101.29} & \multirow{3}{*}{0.13} & \multirow{3}{*}{0.15} \\
\hline & 4.50 & 3.50 & 4.50 & 3.64 & & & & \\
\hline & 4.60 & 3.60 & 4.49 & 3.65 & & & & \\
\hline \multirow{3}{*}{$100 \%$} & 5.00 & 4.00 & 5.05 & 3.97 & \multirow{3}{*}{101.07} & \multirow{3}{*}{99.08} & \multirow{3}{*}{0.11} & \multirow{3}{*}{0.29} \\
\hline & 5.10 & 4.00 & 5.05 & 3.95 & & & & \\
\hline & 5.00 & 4.00 & 5.06 & 3.97 & & & & \\
\hline \multirow{3}{*}{$120 \%$} & 5.50 & 4.40 & 5.49 & 4.39 & \multirow{3}{*}{99.88} & \multirow{3}{*}{99.69} & \multirow{3}{*}{0.10} & \multirow{3}{*}{0.13} \\
\hline & 5.60 & 4.50 & 5.5 & 4.39 & & & & \\
\hline & 5.60 & 4.60 & 5.49 & 4.38 & & & & \\
\hline
\end{tabular}

${ }^{(a)}$ Mean of three replicates.

TABLE 3: Summary of validation parameters of developed HPTLC method.

\begin{tabular}{lcc}
\hline Validation parameters & MET & OLM \\
\hline Linear range $(\eta$ g per band) & $1000-2250$ & $800-1800$ \\
$\mathrm{LOD}^{(\mathrm{a})}(\eta$ g per band) & 249.61 & 210.05 \\
$\mathrm{LOQ}^{(\mathrm{b})}(\eta$ g per band) & 823.72 & 693.15 \\
Accuracy $(\%)$ & $99.85-101.07 \%$ & $99.08-101.29 \%$ \\
Repeatability of measurement of peak area $\left(\mathrm{RSD}^{(\mathrm{c})} \%, n=6\right)$ & 0.1218 & 0.0742 \\
Repeatability of sample application $(\mathrm{RSD} \%, n=6)$ & 0.5823 & 0.2957 \\
Precision $(\mathrm{RSD} \%)$ & & 0.0821 \\
$\quad$ Intraday $(n=3)$ & 0.1547 & 0.0442 \\
$\quad$ Interday $(n=3)$ & 0.1108 & \\
\hline
\end{tabular}

(a) Limit of detection.

(b) Limit of quantification.

(c) Relative standard deviation.

$n=$ number of determinations.

TABLE 4: Results from the robustness study of the method.

\begin{tabular}{|c|c|c|c|}
\hline \multirow{2}{*}{$\begin{array}{l}\text { Method } \\
\text { parameter/condition }\end{array}$} & \multirow{2}{*}{ Deliberate changes } & \multicolumn{2}{|c|}{$\%$ RSD of peak area $(n=3)$} \\
\hline & & MET & OLM \\
\hline \multirow{2}{*}{ Plate activation time $\mathrm{e}^{(\mathrm{a})}$} & $20 \mathrm{~min}$ & 1.24 & 1.01 \\
\hline & $30 \mathrm{~min}$ & 0.43 & 0.36 \\
\hline \multirow{2}{*}{ Chamber saturation time $e^{(a)}$} & $16 \mathrm{~min}$ & 1.64 & 1.71 \\
\hline & $24 \mathrm{~min}$ & 0.86 & 0.80 \\
\hline \multirow{2}{*}{ Volume of mobile phase $\mathrm{e}^{(\mathrm{b})}$} & $8.2 \mathrm{~mL}$ & 1.22 & 1.40 \\
\hline & $10.0 \mathrm{~mL}$ & 0.39 & 0.46 \\
\hline \multirow{2}{*}{ Development distance from spot application ${ }^{(c)}$} & $7.7 \mathrm{~cm}$ & 0.31 & 0.22 \\
\hline & $6.3 \mathrm{~cm}$ & 0.42 & 0.56 \\
\hline
\end{tabular}

(a) $\pm 20 \%$ change in set time.

(b) $\pm 10 \%$ change in set volume.

(c) $\pm 10 \%$ change in set distance.

TABLE 5: Results from analysis of metoprolol succinate and olmesartan medoxomil in the combined tablet dosage form.

\begin{tabular}{lccc}
\hline Capsule & Component & Label claim $(\mathrm{mg})$ & Amount of drug found \pm RSD $(\%)(n=5)$ \\
\hline \multirow{2}{*}{ Brand A } & MET & 25.0 & $100.30 \pm 0.256$ \\
& OLM & 20.0 & $98.20 \pm 0.257$ \\
\multirow{2}{*}{ Brand B } & MET & 25.0 & $99.67 \pm 0.426$ \\
& OLM & 20.0 & $97.25 \pm 0.945$ \\
\hline
\end{tabular}

$n=$ number of determinations. 
3.2.5. Limits of Detection (LOD) and Limits of Quantification (LOQ). The limits of detection (LOD) and quantification (LOQ) for metoprolol succinate were 249.61 and $823.72 \eta \mathrm{g}$ per band, respectively. For olmesartan medoxomil the values were 210.05 and $693.15 \eta$ g per band, respectively, and are listed in Table 3.

3.2.6. Robustness. Acceptable \%RSD values obtained after making small deliberate changes in the developed HPTLC method indicate that the method is robust for the intended purpose as shown in Table 4.

3.2.7. Solution Stability. No significant change was observed in peak area of MET and OLM when analyzed up to $24 \mathrm{~h}$ at different time intervals, (RSD 1.53\%), which indicates the solution stability within the period of evaluation.

3.3. Method Application. The proposed, developed, and validated method was successfully applied to analysis of metoprolol succinate and olmesartan medoxomil in their marketed formulations (brand A and B). There was no interference of excipients commonly found in capsules as described in specificity studies. The assay results obtained were satisfactory, accurate, and precise as indicated by the good recovery and acceptable standard deviation values (Table 5). The good performance of the method indicates that it can be used for the determination of MET and OLM in pharmaceutical formulations.

\section{Conclusion}

This developed and validated method for simultaneous analysis of metoprolol succinate and olmesartan medoxomil in pharmaceutical preparations is very simple, rapid, accurate, and precise. The method was successfully applied for determination of MET and OLM in their pharmaceutical capsule formulations. Moreover, it has advantages of short run time and the possibility of analysis of a large number of samples, both of which significantly reduce the analysis time per sample. Hence, this method can be conveniently used for routine quality control analysis of MET and OLM in their pharmaceutical formulations.

\section{Acknowledgments}

The authors are thankful to Alembic Pharmaceuticals Ltd., Baroda for providing gift samples of metoprolol succinate and olmesartan medoxomil. The authors are very thankful to Sophisticated Instrumentation Center for Applied Research \& Testing (SICART, Vallabh Vidyanagar, India) for providing necessary facilities to carry out research work.

\section{References}

[1] V. G. Dongre, S. B. Shah, P. P. Karmuse, M. Phadke, and V. K. Jadhav, "Simultaneous determination of metoprolol succinate and amlodipine besylate in pharmaceutical dosage form by
HPLC," Journal of Pharmaceutical and Biomedical Analysis, vol. 46, no. 3, pp. 583-586, 2008.

[2] O'Neil, A. Smith, P.E. Heckelman, and S. Budavari, Eds., Merck Index, Merck \& Co., Readington, NJ, USA, 13th edition, 2001.

[3] C. Mustafa, T. Derya, and G. Aysegul, "Spectrophotometric determination of metoprolol tartrate in pharmaceutical dosage forms on complex formation with $\mathrm{Cu}(\mathrm{II})$," Pharmaceuticals, vol. 4, no. 7, pp. 964-975, 2011.

[4] K. V. KannaRao, M. E. Rao, K. E. Nagoji, and S. S. Rao, "Determination of metoprolol tartrate by reverse phase HPLC," Indian Journal of Pharmaceutical Sciences, vol. 65, pp. 204-206, 2002.

[5] M. D. Phale and P. D. Hamrapurkar, "A validated and simplified RP-HPLC of metoprolol succinate from bulk drugs," Asian Journal of Research in Chemistry, vol. 2, no. 2, pp. 119122, 2009.

[6] K. S. Kumar, R. Ravikumar, A. Rajasekaran, and V. Ravichandrana, "Simultaneous spectrophotometric determination of metoprolol," tartrate and ramipril, vol. Digest Journal of Nanomaterials and Biostructures, no. 5, pp. 1-173, 176.

[7] V. G. Dongre, S. B. Shah, P. P. Karmusea, M. Phadke, and V. K. Jadhav, "Simultaneous determination of metoprolol succinate and amlodipine besylate in pharmaceutical dosage form by HPLC," Journal of Pharmaceutical and Biomedical Analysis, vol. 46, no. 3, pp. 583-586, 2008.

[8] B. Singh, D. K. Patel, and S. K. Ghosh, "Development of reverse-phase HPLC method for simultaneous analysis of metoprolol succinate and hydrochlorothiazide in a tablet formulation," Tropical Journal of Pharmaceutical Research, vol. 8, no. 6, pp. 539-543, 2009.

[9] S. B. Wankhede, N. R. Dixit, and S. S. Chitlange, "Stability indicating HPTLC method for quantitative determination of atorvastatin calcium and metoprolol succinate in capsules," Der Pharmacia Lettre, vol. 3, no. 1, pp. 1-7, 2011.

[10] A. K. Sarkar, D. Ghosh, A. Das et al., "Simultaneous determination of metoprolol succinate and amlodipine besylate in human plasma by liquid chromatography-tandem mass spectrometry method and its application in bioequivalence study," Journal of Chromatography B, vol. 873, no. 1, pp. 77$85,2008$.

[11] K. V. Gowda, U. Mandal, P. Senthamil Selvan et al., "Liquid chromatography tandem mass spectrometry method for simultaneous determination of metoprolol tartrate and ramipril in human plasma," Journal of Chromatography B, vol. 858, no. 1-2, pp. 13-21, 2007.

[12] J. Patel, "Development of the UV spectrophotometric method of Olmesartan medoxomil in bulk drug and pharmaceutical formulation and stress degradation studies Pharmaceutical Methods," Pharmaceutical Methods, vol. 2, no. 1, pp. 36-40, 2011.

[13] D. G. T. Parambi, M. Mathew, A. Jose, and K. G. Revikumar, "Estimation of Olmesartan Medoxomil, an angiotensin receptor blocker in pharmaceutical dosage form by U.V.Spectrophotometric method.J. Pharm.Res," Journal of Pharmacy Research, vol. 3, no. 8, pp. 1706-1708, 2010.

[14] P. Mehulkumar, V. Ramesh, V. Vinaykumar, R. Srinivas, and P. V. Diwan, "Simultaneous spectroscopic estimation of amlodipine besylate and olmesartanmedoximil in tablet dosage form," Asian Journal of Research in Chemistry, vol. 2, no. 2, pp. 127-130, 2009.

[15] A. R. Rote and P. D. Bari, "Spectrophotometric estimation of olmesartan medoxomil and hydrochlorothiazide in tablet," Indian Journal of Pharmaceutical Sciences, vol. 72, no. 1, pp. 111-113, 2010. 
[16] P. Jain, A. Jain, D. Maliwal, and V. Jain, "Development and validation of spectrophotometric and RP-HPLC method for estimation of olmesartan medoxomil in tablet dosage form," International Journal of Pharma and Bio Sciences, vol. 1, no. 2, article 21, 2010.

[17] S. S. Qutab, S. N. Razzaq, M. Ashfaq, I. U. Khan, and A. M. Mumtaz, "Simultaneous quantitation of olmesartan medoxomil and amlodipine besylate in combined tablets using HPLC," Journal of the Chilean Chemical Society, vol. 54, no. 3, pp. 234-237, 2009.

[18] K. R. Patila and D. B. Shinde, "Stability indicating LC method for the simultaneous determination of Olmesartan \& Ramipril in dosage form," International Journal of Industrial Chemistry, vol. 2, no. 2, pp. 102-111, 2011. 


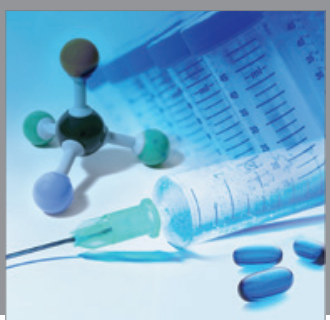

International Journal of

Medicinal Chemistry

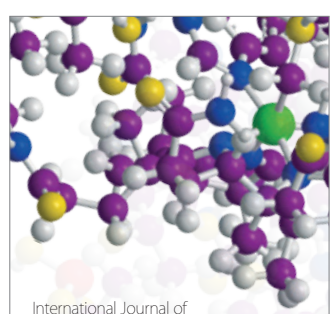

Carbohydrate Chemistry

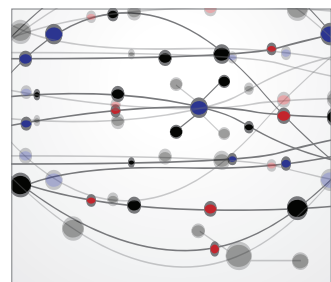

The Scientific World Journal
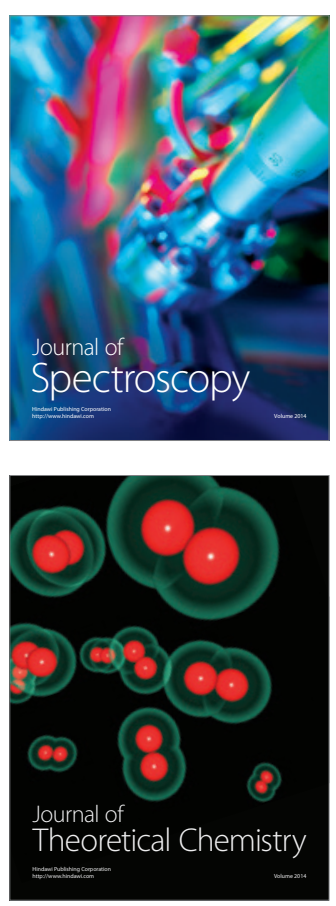
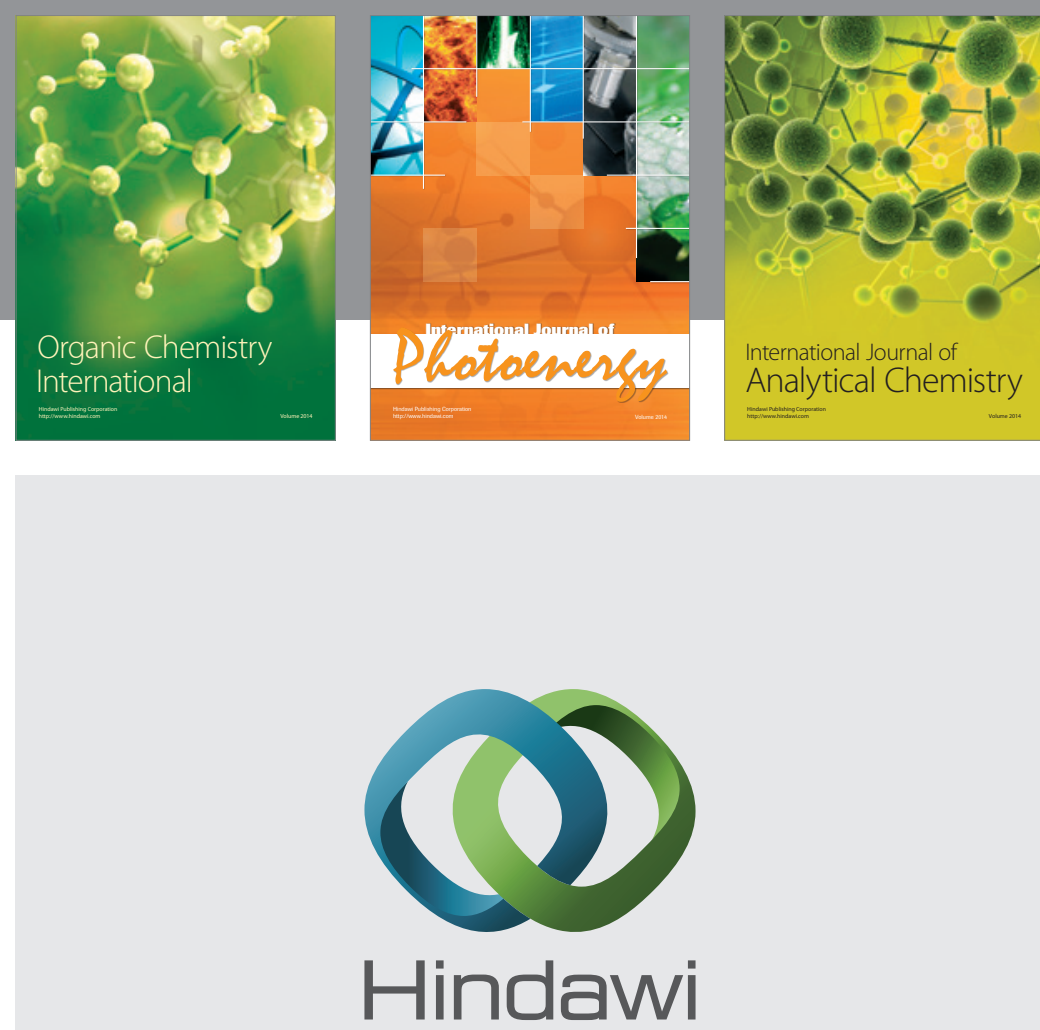

Submit your manuscripts at

http://www.hindawi.com
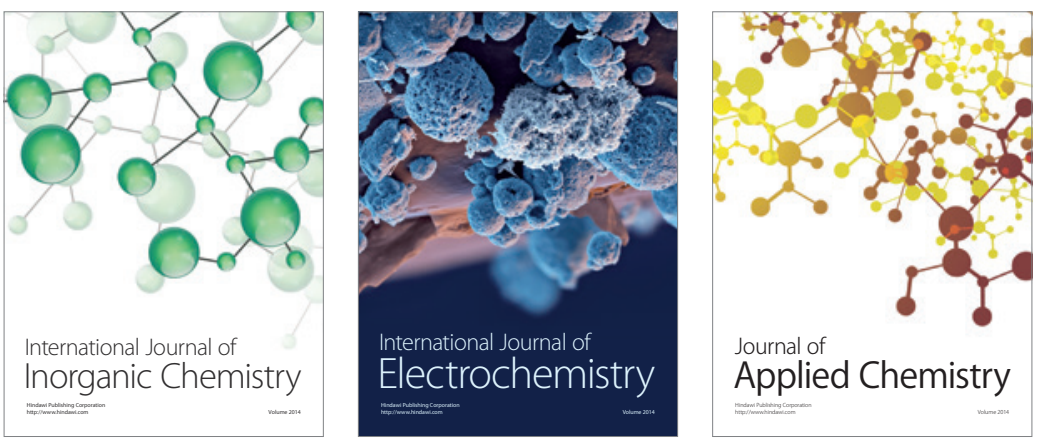

Journal of

Applied Chemistry
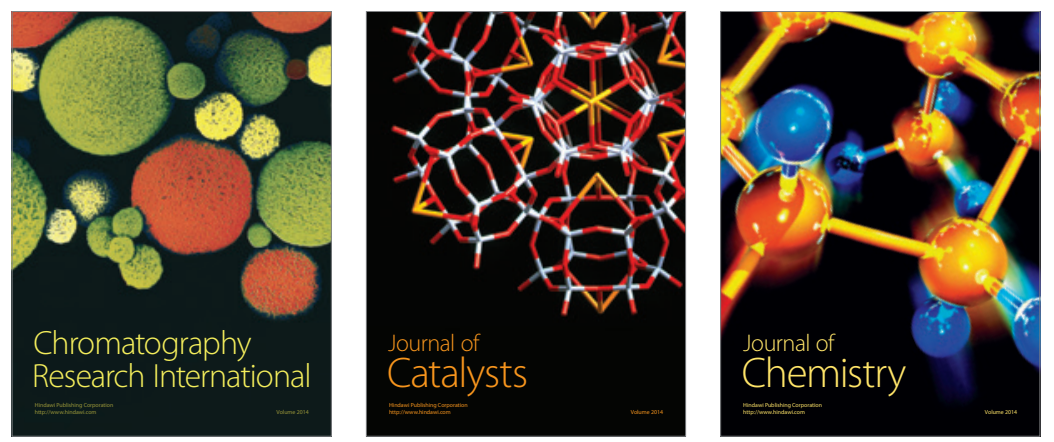
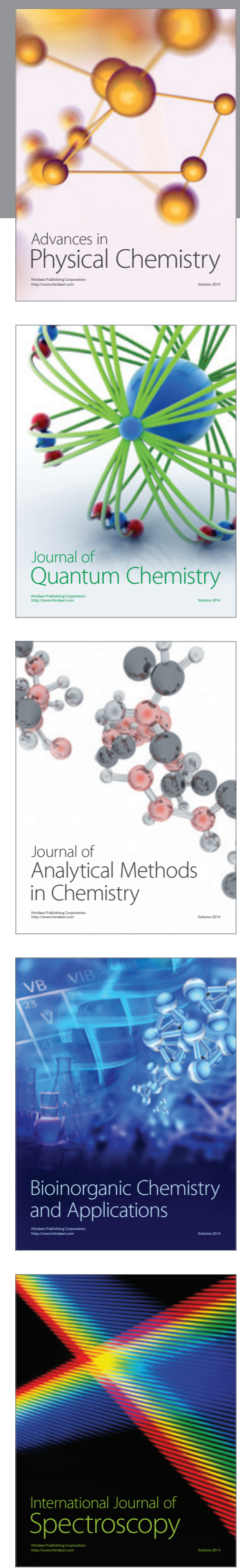